\title{
Inactivation of Pancreatic Stellate Cells by Exendin-4 Inhibits the Migration and Invasion of Pancreatic Cancer Cells
}

This article was published in the following Dove Press journal: OncoTargets and Therapy

\author{
Meizhu Yan ${ }^{1, *}$ \\ Manru Shen ${ }^{1, *}$ \\ Linfang $X u^{1, *}$ \\ Jiying Huang' \\ Guijun $\mathrm{He}^{\prime}$ \\ Min An' \\ Xiaocui $\mathrm{Li}^{\mathrm{I}}$ \\ Zhenjun Gao' \\ Xin Meng ${ }^{2}$
}

'Department of Gastroenterology, Zhongshan Hospital Qingpu Branch, Fudan University, Shanghai 201700, People's Republic of China; ${ }^{2}$ Department of Hospital Infection Management, Zhongshan Hospital Qingpu Branch, Fudan University, Shanghai 201700, People's Republic of China

*These authors contributed equally to this work
Background: Pancreatic stellate cells (PSCs) are precursor cells of cancer-associated fibroblasts that promote tumor proliferation, invasion, and metastasis. The glucagon-like peptide-1 receptor agonist exendin- 4 has been reported to exhibit anticancer effects against several tumor cells; however, the function and mechanism underlying the effects of exendin4 on pancreatic cancer cells remain unclear.

Methods: Gene expression levels were determined using quantitative real-time polymerase chain reaction (qRT-PCR) and Western blot assay. Cell viability, migration and invasion were assessed using the cell counting kit-8 (CCK-8), wound healing, and transwell assays, respectively. A xenografted tumor model was established in mouse to evaluate the effects of exendin-4 in vivo.

Results: Exendin-4 treatment led to the inactivation of PSCs and suppressed their proliferation and migration. Moreover, we also found that exendin- 4 attenuated NF- $\kappa$ B-dependent SDF-1 secretion. Furthermore, pancreatic cancer cells incubated with conditioned medium obtained from exendin-4-treated PSCs showed a decreased ability to proliferate, migrate, and invade as compared to the control cells, which is similar to the effects induced by the CXCR4 inhibitor, AMD3100. Consistent with in vitro results, we also confirmed that exendin-4 indirectly targeted pancreatic cancer cells in vivo by attenuating the function of PSCs and suppressing the deposition of extracellular matrix.

Conclusion: These results revealed that exendin-4-treated PSCs could suppress pancreatic cancer cell proliferation and invasion, offering a potential strategy for the treatment of pancreatic cancer.

Keywords: pancreatic cancer, pancreatic stellate cells, exendin-4, SDF-1

\section{Introduction}

Pancreatic cancer is currently one of the most severe gastrointestinal malignancies and most lethal human malignancies, with a steadily increasing incidence rate and a five-year survival rate of $9 \% .^{1-3}$ A major characteristic of pancreatic cancer is excessive desmoplasia, which is characterized by fibrous or connective tissue growth and altered tumor stroma, and is correlated with poor prognosis. ${ }^{4}$ The interactions between the tumor and stromal cells play a critical role in tumor progression. ${ }^{5}$ Increasing evidence shows that pancreatic desmoplastic stroma is a pivotal factor in tumorigenesis, metastasis, and chemotherapy resistance of pancreatic cancer. ${ }^{6-8}$ As a main component of the tumor stroma, pancreatic stellate cells (PSCs) may participate in the development of pancreatic cancer. ${ }^{9}$
Department of Gastroenterology,

Zhongshan Hospital Qingpu Branch,

Fudan University, II 58 East Gongyuan

Road, Shanghai 201700, People's Republic

Xin Meng

Department of Hospital Infection Management, Zhongshan Hospital Qingpu

Branch, Fudan University, 1158 East

Gongyuan Road, Shanghai 201700,

People's Republic of China

Tel +86-2I-69719190-55I5

Email qphospital_mx@I26.com 
PSCs, which are mainly distributed in the glands and lobules of the pancreas as well as around the blood vessels and capillaries, play an important role in the development of pancreatic fibrosis and have been proven to be involved in the formation of pancreatic tumor microenvironment. ${ }^{10,11}$ Continuous activation of PSCs can disturb the biomechanical balance of the tumor microenvironment, which is conducive to the invasion of cancer cells. ${ }^{12}$ Recent studies have demonstrated that PSCs can interact with pancreatic cancer cells to promote cell proliferation and suppress cell apoptosis. ${ }^{13}$ In addition, pancreatic cancer cells can promote the activation of PSCs. ${ }^{14}$ Accumulating evidence reveals that PSCs interact closely with cancer cells as well as with other cell types of the stroma, to set up a growth permissive microenvironment for pancreatic tumours, which accelerates local tumour growth as well as distant metastasis. ${ }^{15}$ Therefore, understanding the mechanisms underlying the interaction between PSCs and pancreatic cancer cells is crucial for the development of effective therapeutic techniques.

Glucagon-like peptide-1 (GLP-1) is a gut-derived incretin that exerts pleiotropic functions through peripheral GLP-1 receptors (GLP-1R). GLP-1R are of clinical importance due to their physiological expression and functions in the pancreatic islet cells, potential in diabetes therapy, as well as role in cancer. ${ }^{16}$ GLP-1R activation inhibits growth and augments apoptosis in murine CT26 colon cancer cells. ${ }^{17}$ Exendin-4 is a 39-amino acid peptide that shares approximately 53\% homology with mammalian incretin GLP-1 and binds to and activates mammalian GLP-1R on pancreatic $\beta$ cells. ${ }^{18}$ Previous reports have shown that exendin- 4 acts as a tumor suppressor in several types of cancers. For example, exendin-4 attenuated breast cancer cell growth by inhibiting NF- $\mathrm{KB}$ activation; ${ }^{19}$ in ovarian cancer cells, exendin-4 inhibited growth and augmented apoptosis. ${ }^{20}$ Additionally, exendin-4 inhibits glioma cell migration, invasion, and epithelial-tomesenchymal transition through the GLP-1R/SIRT3 pathway. ${ }^{21}$ To date, however, no studies have analyzed the effects of exendin-4 on PSCs derived from pancreatic cancer tissues.

In this study, we found that exendin-4 treatment of PSCs led to their inactivation, suppressed their proliferation and migration, and decreased NF- $\mathrm{kB}-\mathrm{dependent} \mathrm{SDF-1} \mathrm{produc-}$ tion. In addition, we demonstrated that conditioned medium (CM) from exendin-4-treated PSCs suppressed pancreatic cancer cell proliferation and invasion, compared to $\mathrm{CM}$ from untreated PSCs. We confirmed that exendin-4 indirectly targets pancreatic cancer cells by attenuating the function of
PSCs and suppressing extracellular matrix (ECM) deposition.

\section{Materials and Methods Cell Culture}

Human pancreatic cancer cell lines PANC-1 and SW1990 were purchased from Cell Bank of Type Culture Collection of the Chinese Academy of Sciences (Shanghai, China) and cultured in DMEM (Gibco, Grand Island, NY, USA) supplemented with $10 \%$ fetal bovine serum (FBS; Gibco). Human PSCs were isolated from primary pancreatic cancer specimens using the explantation method as previously reported. ${ }^{22}$ Sample collection was conducted according to the protocol approved by the Institutional Review Board of the Qingpu Branch of Zhongshan Hospital (2019-30), and written informed consent was obtained from each patient. The purity of cells was assessed based on morphology and cytofilament staining of $\alpha$-smooth muscle actin ( $\alpha$-SMA) and collagen I (Coll-I). Cells at $80 \%$ confluency between passages 3 and 6 were used for this study.

\section{RNA Extraction and Quantitative Real- Time Polymerase Chain Reaction (qRT- PCR)}

Total RNA was isolated using Trizol reagent and then reverse transcribed to complementary DNA (cDNA) using the PrimeScript RT Reagent Kit (Takara, Dalian, China). Real-time PCR was carried out on an ABI 7900 sequence detection system (Applied Biosystems, Foster City, CA, USA) using SYBR Premix Ex Taq (Takara). $G A P D H$ was used as the reference gene. Relative expression levels were calculated using the $2^{-\Delta \Delta C T}$ method, and all experiments were conducted in triplicate.

\section{Western Blotting}

Total protein was extracted from cells lysed using RIPA buffer (Beyotime, Shanghai, China). Total proteins were separated using gel electrophoresis and then transferred onto a PVDF membrane. The membrane was washed in TBST and incubated with anti- $\alpha$-SMA (Proteintech, Wuhan, China), anti-collagen I (Coll-I) (Proteintech), antip65 (Cell Signaling Technology [CST], Beverly, MA, USA), anti-phospho-p65 (CST), anti-IкB- $\alpha$ (CST), or anti-p-IкB- $\alpha$ (CST) at $4{ }^{\circ} \mathrm{C}$ overnight. After incubation with the secondary antibody (Abcam, Cambridge, UK), bands were visualized and quantified using the Odyssey Infrared Imaging System (LI-COR Biosciences, Lincoln, NE, USA). 


\section{Preparation of CM from Exendin-4- Treated PSCs}

PSCs were cultured in serum-free DMEM with or without exendin-4 for $48 \mathrm{~h}$. After $48 \mathrm{~h}$ of incubation with serumfree medium, the medium was collected and considered $\mathrm{CM}$. After collection, $\mathrm{CM}$ was centrifuged for $10 \mathrm{~min}$ at $1000 \mathrm{rpm}$ and stored at $-80^{\circ} \mathrm{C}$ until use.

\section{Cell Proliferation}

Cell proliferation was measured using the cell counting kit-8 (CCK-8; Dojindo, Kumamoto, Japan) assay. To determine the proliferation of PSCs, cells were seeded onto 96-well plates in DMEM containing 10\% FBS and cultured for $12 \mathrm{~h}$. Then, the medium was replaced with fresh DMEM containing 2\% FBS with or without exendin4, followed by incubation for $72 \mathrm{~h}$. To determine the proliferation of pancreatic cancer cells, cells were cultured in CM from PSCs or exendin-4-treated PSCs containing $2 \%$ FBS for $72 \mathrm{~h}$. CCK-8 solution was added at $20 \mu \mathrm{L}$ per well and the plates were incubated for $4 \mathrm{~h}$. Absorbance was measured on a microplate reader (Beckman Coulter, Brea, CA, USA) at $490 \mathrm{~nm}$.

\section{Wound-Healing Assay}

To assess the migration and wound-healing ability of PSCs, cells were seeded onto a 24 -well plate, and a scratch was made on the wells using a $200-\mu \mathrm{L}$ pipette tip fixed in a custom-made holder. Cells were washed to remove all detached cells and incubated with fresh serum-free medium. Wound width was measured $36 \mathrm{~h}$ after the scratch was made.

\section{Transwell Migration and Invasion Assays}

Migration and invasion assays were performed according to a standard method previously described. ${ }^{23}$ Cells were first cultured in CM from PSCs or exendin-4-treated PSCs containing 2\% FBS for $24 \mathrm{~h}$. Transwell permeable supports (8.0$\mu \mathrm{m}$ pore size; Corning, Kennebunk, ME, USA) were used to determine the cell migration and invasion ability. Briefly, 1.5 $\times 10^{5}$ cells were seeded in the top chamber with CM from PSCs or exendin-4-treated PSCs. For the invasion assay, chambers coated with Matrigel (Corning) were used. Culture medium supplemented with $10 \%$ FBS was added to the bottom of chamber as a chemoattractant. After $24 \mathrm{~h}$ of incubation at $37^{\circ} \mathrm{C}$, the migratory or invading cells on the lower surface of the filter were stained with crystal violet and quantified using Image-Pro Plus 7.0 software (Media Cybernetics, Rockville, MD, USA).

\section{Immunofluorescence Staining Assay}

Sterilized coverslips were placed on a 6-well plate, and the cell suspension was added to the coverslips. The cells were fixed with 2-4\% formaldehyde in PBS and incubated with primary antibody overnight at room temperature. Next, the cells were rinsed thrice with PBS and were incubated with fluorochrome-conjugated diluted secondary antibody in the dark for 1-2 $\mathrm{h}$. An appropriate amount of antifluorescence quencher was added to seal the film. The acquired image was then observed under a fluorescence microscope.

\section{In vivo Experiments}

For in vivo studies, PANC-1 cells or/and PSCs suspended in DMEM were injected subcutaneously into the flanks of nude mice. One week after implantation, mice were treated with either saline solution or exendin-4 at a dose of $1 \mathrm{nmol} / \mathrm{kg}$ administered intraperitoneally daily for 3 weeks $(n=4 /$ group). All mice were euthanized, and the tumors were excised and weighed. Tumor size was measured with a slide caliper, and tumor volume was estimated using the following formula: volume $=$ length $\times$ width $^{2} \times 0.5$. All animal handling procedures were approved by the Experimental Animal Ethics Committee of Fudan University (Shanghai, China) and were consistent with the National Institutes of Health Guide for the Care and Use of Laboratory Animals.

\section{Immunohistochemistry (IHC)}

IHC was performed according to a standard method previously described. ${ }^{23}$ Briefly, paraffin-embedded sections were incubated with anti-Ki67 (Proteintech) and anti- $\alpha$-SMA (Proteintech) primary antibodies for $12 \mathrm{~h}$ at $4^{\circ} \mathrm{C}$ after blocking with $0.5 \%$ non-fat milk. After washing with PBS, the sections were incubated with an HRP-conjugated secondary antibody at $37^{\circ} \mathrm{C}$ for $30 \mathrm{~min}$. Then, sections were immersed in 3.3diaminobenzidine solution for $3 \mathrm{~min}$, and nuclei were counterstained with $10 \%$ Mayer's hematoxylin. Finally, tissues were dehydrated and mounted in crystal mount. Proliferative rate was detected as the mean percentage of nuclei staining positive for Ki67 antigen in 1000 cells under a microscope. Three randomly selected fields of view for each mouse were included in the calculation of the proliferative rate. $\alpha$-SMA expression in tissues was stained using IHC, the difference of $\alpha$-SMA expression in tissues was statistically analyzed.

\section{Statistics}

All experiments were performed independently in triplicate, and results were expressed as means \pm SD. 
A

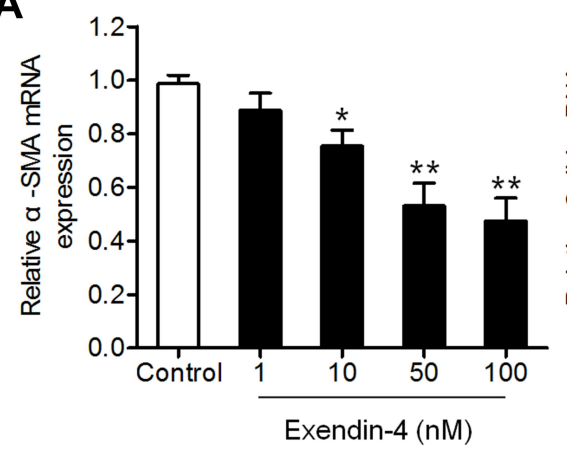

C

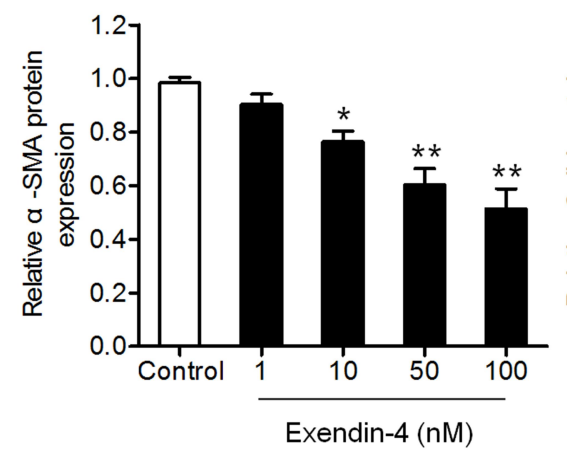

E

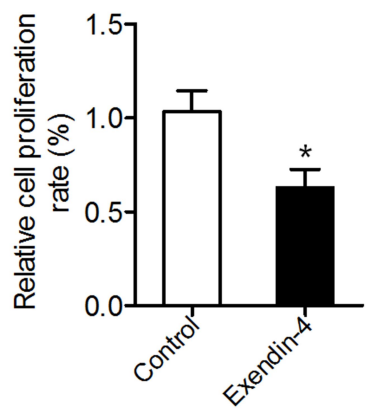

B

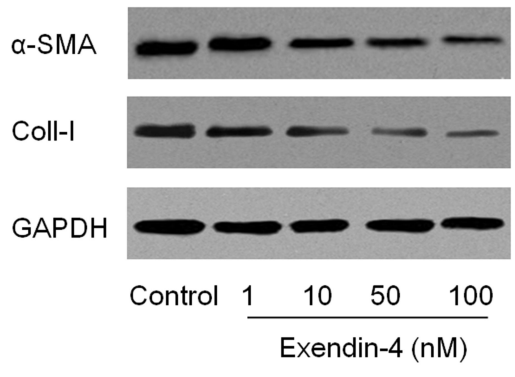

D

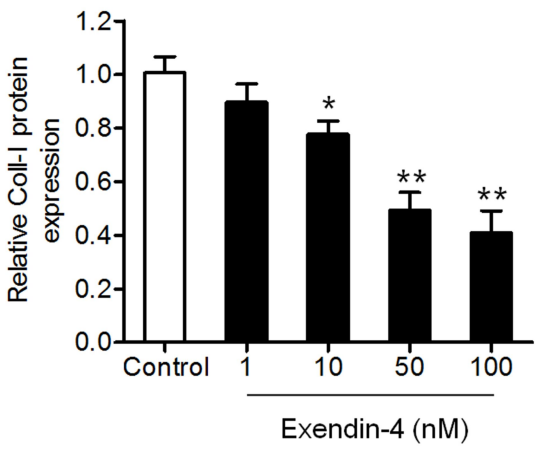

F

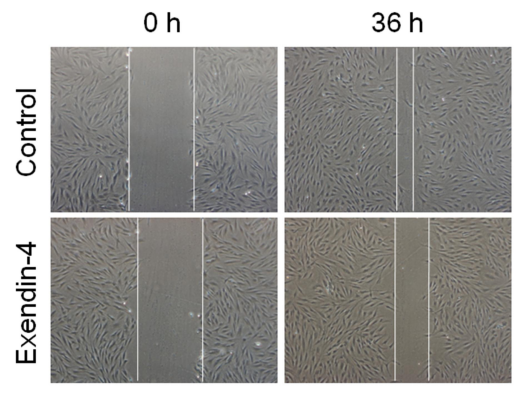

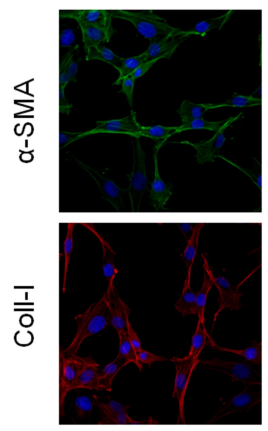

Control

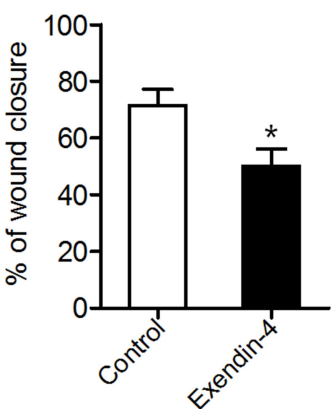

Figure I Exendin-4 inhibits the activation and function of PSCs. (A-C) PSCs were treated with different doses of exendin-4 for $48 \mathrm{~h}$. (A) mRNA expression of $\alpha$-SMA and Coll-I determined using qRT-PCR $(* P<0.05, * * P<0.0$ I, by Student's $t$-test vs control). (B) Protein expression of $\alpha$-SMA and Coll-I detected by Western blot. (C) Relative quantitative comparison of Western blot analysis $(* P<0.05, * * P<0.01$, by Student's $t$-test vs control). (D) Immunofluorescence staining of $\alpha$-SMA and Coll-I in PSCs after treatment with $50 \mathrm{nM}$ exendin-4. Representative images are shown at 300x magnification. Scale bar: $50 \mu \mathrm{m}$ (E) Cell viability of PSCs treated with or without exendin-4 determined by CCK- 8 assay $(* P<0.05$, by Student's $t$-test vs control). $(\mathbf{F})$ Cell migration evaluated by wound-healing assay $(* P<0.05$, by Student's $t$-test vs control). Data represent mean \pm SD from three independent experiments.

Significance was analyzed using the Student's $t$-test. Statistical analysis was carried out using GraphPad Prism 5.0 (La Jolla, CA, USA). $P<0.05$ was considered statistically significant.

\section{Results}

\section{Exendin-4 Inhibited the Activation of PSCs}

We first investigated the effect of exendin-4 on PSC activation. PSCs were treated with different concentrations of exendin- $4(1,10,50$ and $100 \mathrm{nM})$ for $48 \mathrm{~h}$, and then the levels of PSC activation biomarkers $\alpha$-SMA and Coll-I were measured. qRT-PCR results showed that exendin- 4 treatment significantly decreased the mRNA expression of $\alpha$-SMA and Coll-I (Figure 1A). Decreased protein levels of $\alpha$-SMA and Coll-I were also observed in PSCs after exendin-4 treatment based on Western blot analysis (Figure 1B and C). Results of IHC were similar to those of Western blot (Figure 1D). These results confirmed that exendin-4 has the ability to inhibit PSC activation. 


\section{Exendin-4 Suppressed PSC Function}

We further explored whether exendin-4 treatment affects the function of PSCs, including cell growth and migration. CCK-8 assay showed that exendin-4 suppressed the growth of PSCs compared to that of control cells (Figure 1E). In addition, the migration ability of PSCs was determined using a transwell wound-healing assay, which showed that cell migration was significantly attenuated in PSCs after exendin-4 treatment (Figure 1F). These results revealed that exendin- 4 has suppressive effects on PSC growth and migration.

\section{Exendin-4 Attenuated NF-KB-Mediated SDF-I Secretion}

Given that exendin- 4 inhibits NF- $\mathrm{KB}$ activation in several cancer cells, ${ }^{19,24}$ we measured the levels of p65 and phospho-p65 (p-p65) in PSCs with or without exendin-4 treatment. As shown in Figure 2A and B, exendin-4 suppressed the expression of p-p65 and p-IкB $\alpha$ and enhanced that of I $\mathrm{B} \alpha$. The expression of nuclear NF- $\mathrm{\kappa B}$ was consistently inhibited in PSCs after exendin-4 treatment (Figure 2C), suggesting that exendin-4 inhibits NF- $\mathrm{KB}$ activation. Furthermore, we measured the expression of SDF-1 (CXCL12), a downstream cytokine of NF- $\mathrm{kB}$ signaling, ${ }^{25}$ in PSCs with or without exendin-4 treatment. Results of qRT-PCR and ELISA showed that PSCs expressed and secreted decreased amounts of SDF-1 after exendin-4 treatment, which is similar to the effects induced by the NF- $\kappa B$ inhibitor PDTC (Figure 2D and E). These results suggested that exendin- 4 could attenuateNF- $\kappa \mathrm{B}$-dependent SDF-1 secretion.

\section{CM from Exendin-4-Treated PSCs Inhibited Pancreatic Cancer Cell Proliferation, Migration, and Invasion}

Activated PSCs are considered precursor cells of cancerassociated fibroblasts, which can exert a profound impact on pancreatic cancer cells and induce tumor progression. ${ }^{26}$ Therefore, the influence of the regulation of PSC secretome by exendin- 4 on pancreatic cancer cells was explored. As shown in Figure 3A, CM from exendin-4treated PSCs inhibited the proliferation of pancreatic
A

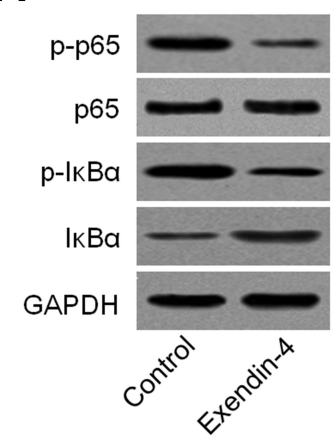

C

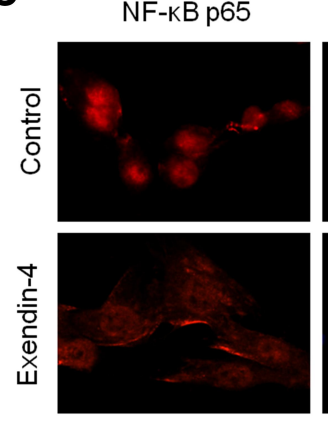

B
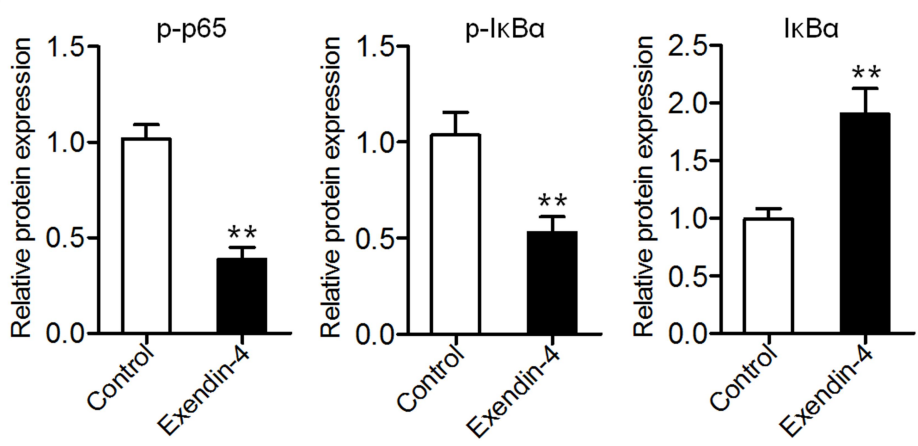

$\mathrm{E}$

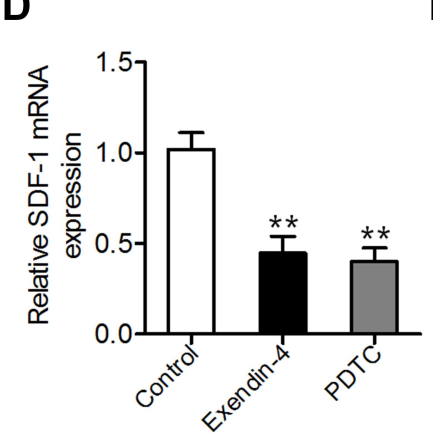

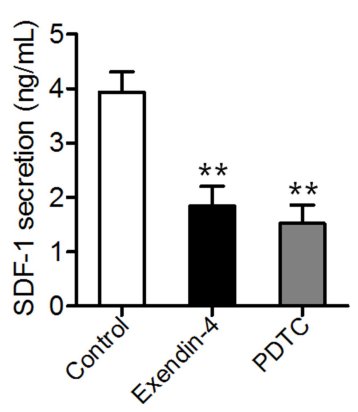

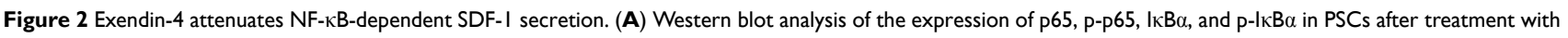
$50 \mathrm{nM}$ exendin-4. (B) Relative quantitative comparison of Western blot analysis (**P<0.0I, by Student's $t$-test vs control). (C) Immunofluorescence staining of NF- $\kappa B$ p65 in PSCs after treatment with $50 \mathrm{nM}$ exendin-4. Representative images are shown at $600 \times$ magnification. Scale bar: $20 \mu \mathrm{m}$. (D) qRT-PCR analysis of SDF-I expression in PSCs treated with $50 \mathrm{nM}$ exendin- 4 or $50 \mu \mathrm{M}$ of the NF-KB inhibitor PDTC ( $* * P<0.0 \mathrm{I}$, by Student's $t$-test vs control). (E) SDF-I content in medium assessed by ELISA (**P<0.0I, by Student's $t$-test vs control). Data represent mean \pm SD from three independent experiments. 
A

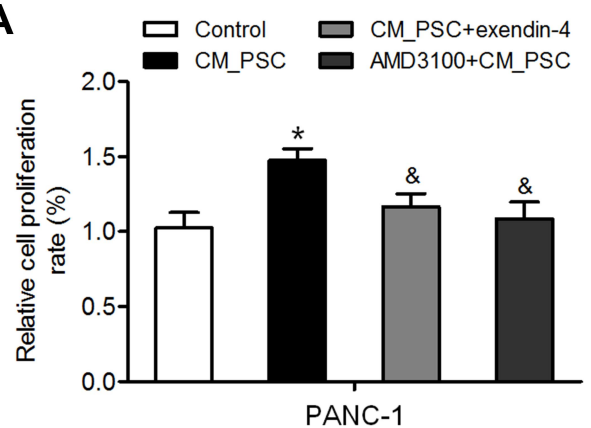

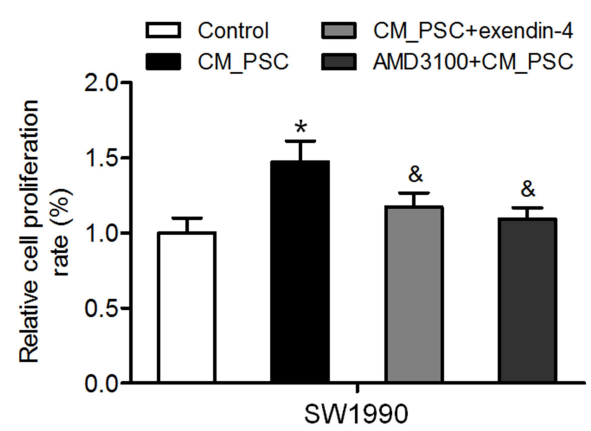

B
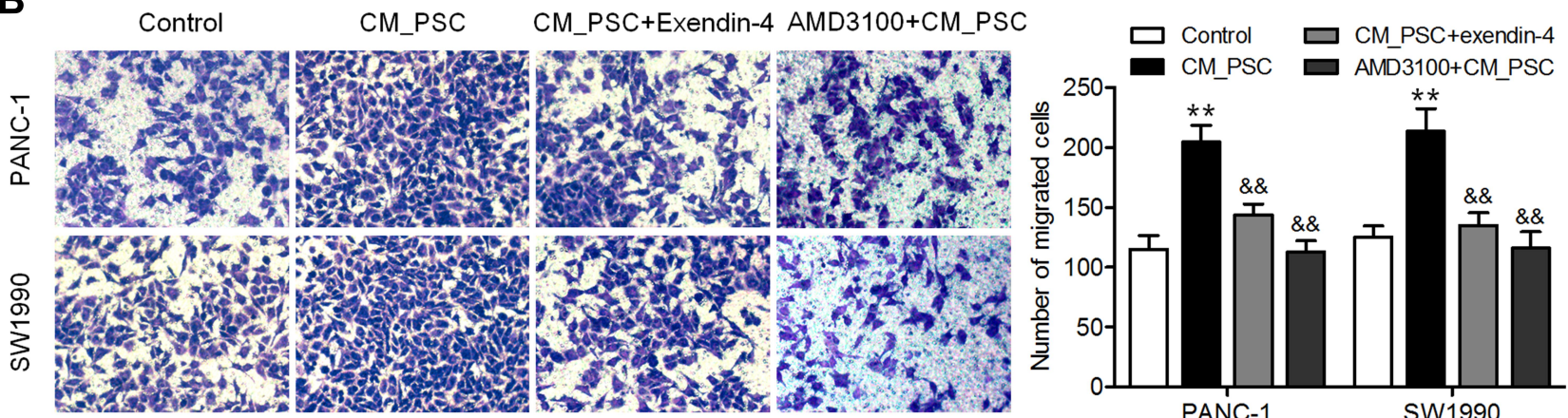

C
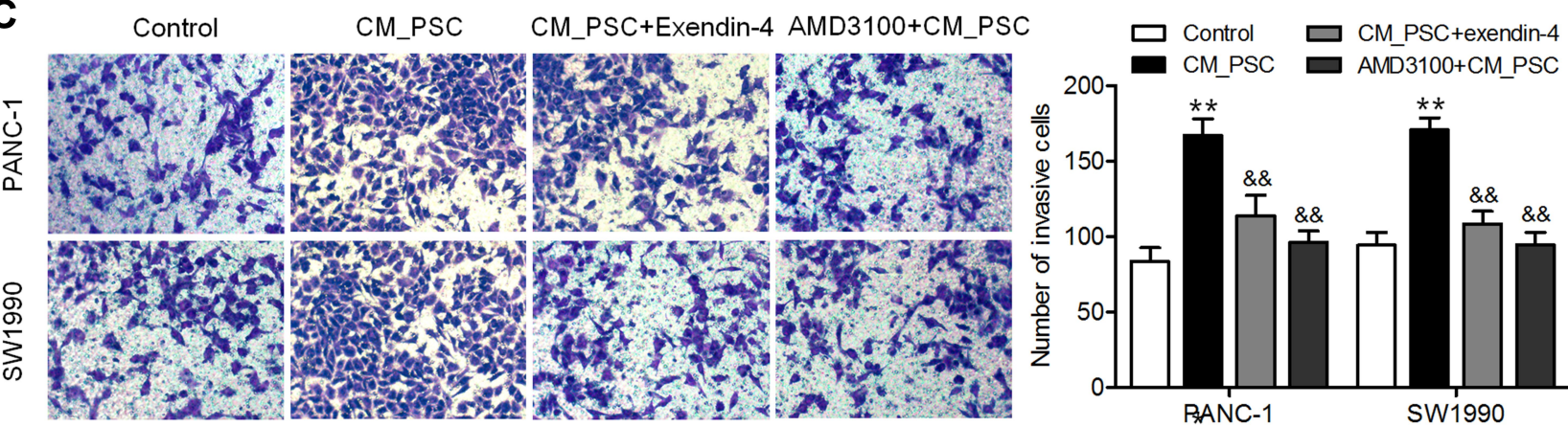

Figure 3 CM from exendin-4-treated PSCs inhibits pancreatic cancer cell proliferation, migration, and invasion. PANC-I and SWI990 cells were incubated with CM from PSCs or exendin-4-treated PSCs, or AMD3100-treated cells were incubated with CM from PSCs. (A) Cell proliferation determined by CCK-8 assay ( $* P<0.05$, by Student's $t$-test vs control; ${ }^{\circledR} P<0.05$, by Student's $t$-test vs CM_PSC). (B) Cell migration determined by Transwell migration assay $\left(* * P<0.0\right.$, by Student's $t$-test vs control; ${ }^{\& \&} P<0.0$ I, by Student's $t$-test vs CM_PSC). (C) Cell invasion determined by Transwell invasion assay $\left(* * P<0.0\right.$ I, by Student's $t$-test vs control; ${ }^{2 \&} P<0.0$, by Student's $t$-test vs CM_PSC). Data represent mean \pm SD from three independent experiments.

cancer cell lines PANC-1 and SW1990 compared to CM from PSCs. Furthermore, PANC-1 and SW1990 cells incubated with $\mathrm{CM}$ obtained from exendin-4-treated PSCs showed a decreased ability to migrate and invade compared to those incubated with $\mathrm{CM}$ from untreated PSCs (Figure 3B and C). Notably, CXCR4 inhibitor AMD3100treated pancreatic cancer cells incubated with $\mathrm{CM}$ obtained from PSCs showed effects that were similar to those induced by $\mathrm{CM}$ obtained from exendin-4-treated PSCs (Figure 3A-C). These results demonstrated that exendin-4-treated PSCs could suppress the proliferation, migration, and invasion of pancreatic cancer cells.

\section{Exendin-4 Inhibited Subcutaneous Tumor Formation in Mice Co-Transplanted with PANC-I Cells and PSCs}

To validate our in vitro results, in vivo experiments were performed using nude mice. Mice were transplanted with PANC-1 cells or/and PSCs; one week later, exendin-4 was administered intraperitoneally each day for three weeks. As shown in Figure 4A-C, treatment with exendin-4 significantly suppressed the growth and weight of tumors consisting of PANC-1 cells co-implanted with PSCs compared to those of control tumors. Furthermore, exendin-4 significantly reduced the Ki67 index and $\alpha$-SMA expression level in 
A

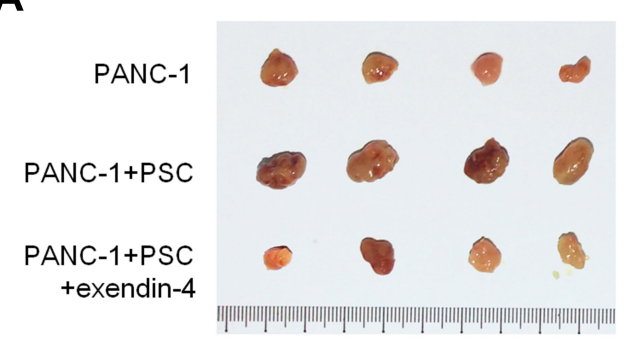

B

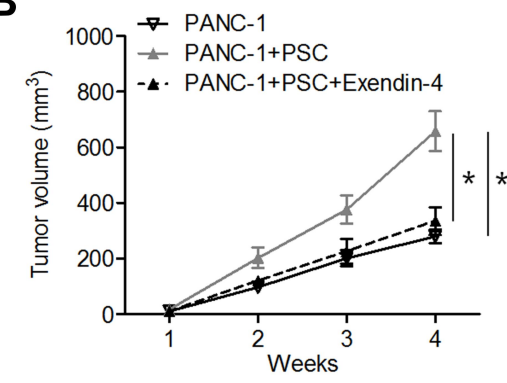

C

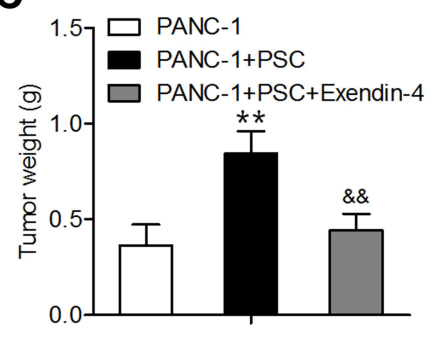

D
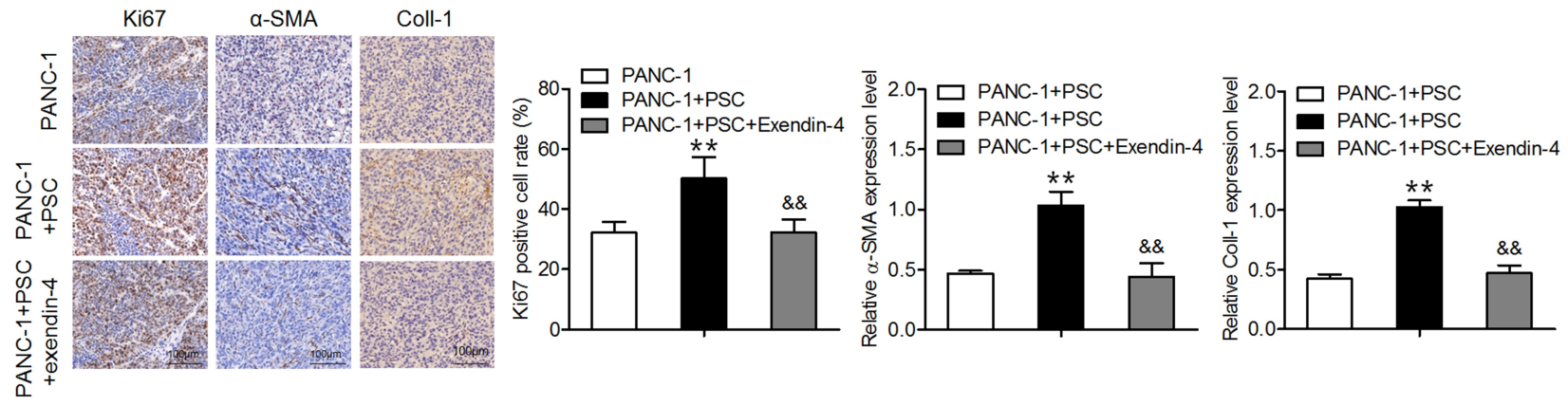

Figure 4 Exendin-4 suppresses subcutaneous tumor formation in nude mice. PANC-I cells or/and PSCs were subcutaneously injected into nude mice. One week later, the mice were intraperitoneally administered with exendin-4 daily for three weeks. (A) Photograph of xenograft tumor masses. (B) Volume of $x e n o g r a f t$ tumors $(* P<0.05$, by Student's $t$-test). (C) Weight of xenograft tumors (**P<0.0I, by Student's $t$-test vs PANC-I; ${ }^{\& \&} P<0.01$, by Student's $t$-test vs PANC-I+PSC). (D) Immunostaining for Ki67, Coll-I and $\alpha$-SMA in tumor tissues (**P<0.0I, by Student's $t$-test vs PANC-I; ${ }^{\& \&} P<0.01$, by Student's $t$-test vs PANC-I+PSC). All results were analyzed using Student's $t$-test. Data represent mean \pm SD from three independent experiments.

tumors consisting of PANC-1 cells co-implanted with PSCs (Figure 4D). These observations indicate that exendin-4 indirectly targeted pancreatic cancer cells by attenuating the function of PSCs and by suppressing ECM deposition.

\section{Discussion}

In the present study, we showed that exendin-4, a GLP-1R agonist, acts as a regulator of PSC differentiation and antitumor functions in pancreatic cancer. Our results showed that exendin-4 treatment led to PSC deactivation and suppressed their proliferation and migration, as well as mildly inhibited the secretion of NF- $\kappa B$-dependent SDF-1. Moreover, exendin-4-treated PSCs suppressed pancreatic cancer cell proliferation, migration, and invasion. These observations suggested that exendin- 4 could inhibit ECM production and paracrine effect of PSCs. Further study on the effect of exendin-4 on tumor in relation to SDF-1 secretion shall be carried out in the near future.

It is well known that tumor microenvironment has key functions in cancer progression. ${ }^{27}$ The pancreatic tumor microenvironment is composed of stellate cells, fibroblasts, and other cells. The interaction between the tumor microenvironment and pancreatic cancer cells has been widely reported. ${ }^{28}$ PSCs, which exist mainly in the forms of resting and activated cells, are one of the important cellular components in the stroma and the main progenitors of cancerassociated fibroblasts in pancreatic cancer. ${ }^{29}$ Quiescent PSCs have the ability to store cytoplasmic lipids, which are usually present in connective tissue in small quantities, and secrete only a small amount of ECM components for the maintenance of normal tissue architecture. ${ }^{30}$ However, during malignancy, quiescent PSCs are activated and subsequently proliferate rapidly and secrete high amounts of ECM, including Coll-I and fibronectin, which stimulate tumor progression, metastasis, and drug resistance. ${ }^{31,32}$ Any agents that affect PSC activation could become potential candidates for the treatment of pancreatic fibrosis. In this study, we demonstrated that exendin-4 treatment significantly decreased the expression of PSC activation biomarkers $\alpha$-SMA and Coll-I. Furthermore, we revealed that exendin-4 suppressed PSC proliferation and migration.

Previous reports have shown that exendin-4 inhibits $\mathrm{NF}-\kappa \mathrm{B}$ activation in ovarian and breast cancer cells, thus inducing cell death and suppression of migration and invasion. ${ }^{19,24}$ As a downstream cytokine of NF- $\kappa B$ signaling, SDF-1 and its receptor CXCR4 play an important role in pancreatic cancer progression. Our previous study showed that SDF-1 is predominantly expressed in PSCs, 
and its upregulation in PSCs increases the invasion of pancreatic cancer cells. ${ }^{33}$ However, in this study, we did not find statistically meaningful evidence to prove that exendin-4 inhibited NF- $\kappa$ B activation and downregulated the secretion of SDF-1 in PSCs. Nevertheless, our results clearly indicated that pancreatic cancer cells incubated with CM obtained from exendin-4-treated PSCs showed a decreased ability to proliferate, migrate, and invade compared to those incubated with $\mathrm{CM}$ from untreated PSCs; these effects were similar to those induced by CXCR4 inhibitor AMD3100. Results from in vivo assay also confirmed that exendin-4 indirectly targets pancreatic cancer cells by attenuating the function of PSCs and suppressing the deposition of ECM.

In conclusion, we have demonstrated that exendin-4 inhibits the biological activity of PSCsand downregulates the proliferation and invasion of pancreatic cancer cells. These observations provide significant insights into the mechanism by which the tumor microenvironment mediates tumor progression, as well as potential targets for the treatment of pancreatic cancer.

\section{Acknowledgments}

This study was supported by funds from the Shanghai Municipal Health Commission (201940371) and Zhongshan Hospital Qingpu Branch Research Project (QYP2019-01).

\section{Disclosure}

The authors report no conflicts of interest.

\section{References}

1. Carmicheal J, Patel A, Dalal V, et al. Elevating pancreatic cystic lesion stratification: current and future pancreatic cancer biomarker(s). Biochimica Et Biophysica Acta Rev Cancer. 2020;1873(1):188318. doi:10.1016/j.bbcan.2019.188318

2. Oneda E, Zaniboni A. Are We Sure that Adjuvant Chemotherapy is the Best Approach for Resectable Pancreatic Cancer? Are We in the Era of Neoadjuvant Treatment? A Review of Current Literature. J Clin Med. 2019;8(11):1922. doi:10.3390/jcm8111922

3. Dell'Oro M, Short M, Wilson P, et al. Clinical Limitations of Photon, Proton and Carbon Ion Therapy for Pancreatic Cancer. Cancers. 2020;12(1):163. doi:10.3390/cancers 12010163

4. Watanabe I, Hasebe T, Sasaki S, et al. Advanced pancreatic ductal cancer: fibrotic focus and beta-catenin expression correlate with outcome. Pancreas. 2003;26(4):326-333. doi:10.1097/00006676-200 305000-00003

5. Whatcott C, Han H, Posner RG, et al. Tumor-stromal interactions in pancreatic cancer. Crit Rev Oncog. 2013;18(1-2):135-151. doi:10.1615/critrevoncog.v18.i1-2.80

6. Martinez-Bosch N, Fernandez-Barrena MG, Moreno M, et al. Galectin-1 drives pancreatic carcinogenesis through stroma remodeling and Hedgehog signaling activation. Cancer Res. 2014;74 (13):3512-3524. doi:10.1158/0008-5472.CAN-13-3013
7. Ernsting MJ, Hoang B, Lohse I, et al. Targeting of metastasis-promoting tumor-associated fibroblasts and modulation of pancreatic tumor-associated stroma with a carboxymethylcellulose-docetaxel nanoparticle. J Control Release. 2015;206:122-130. doi:10.1016/j. jconrel.2015.03.023

8. Liang C, Shi S, Meng Q, et al. Complex roles of the stroma in the intrinsic resistance to gemcitabine in pancreatic cancer: where we are and where we are going. Exp Mol Med. 2017;49(12):e406. doi:10.1038/emm.2017.255

9. Wang HC, Lin YL, Hsu CC, et al. Pancreatic stellate cells activated by mutant KRAS-mediated PAI-1 upregulation foster pancreatic cancer progression via IL-8. Theranostics. 2019;9(24):7168-7183. doi:10.7150/thno.36830

10. Suetsugu A, Snyder CS, Moriwaki H, et al. Imaging the Interaction of Pancreatic Cancer and Stellate Cells in the Tumor Microenvironment during Metastasis. Anticancer Res. 2015;35 (5):2545-2551.

11. Farrow B, Albo D, Berger DH. The role of the tumor microenvironment in the progression of pancreatic cancer. J Surg Res. 2008;149 (2):319-328. doi:10.1016/j.jss.2007.12.757

12. Chronopoulos A, Robinson B, Sarper M, et al. ATRA mechanically reprograms pancreatic stellate cells to suppress matrix remodelling and inhibit cancer cell invasion. Nat Commun. 2016;7(1):12630. doi: $10.1038 /$ ncomms 12630

13. Yu L, Li JJ, Liang XL, et al. PSME3 Promotes TGFB1 Secretion by Pancreatic Cancer Cells to Induce Pancreatic Stellate Cell Proliferation. $J$ Cancer. 2019;10(9):2128-2138. doi:10.7150/ jca.30235

14. Ferdek PE, Jakubowska MA. Biology of pancreatic stellate cellsmore than just pancreatic cancer. Pflugers Archiv. 2017;469:10391050. doi:10.1007/s00424-017-1968-0

15. Pothula SP, Pirola RC, Wilson JS, et al. Pancreatic stellate cells: aiding and abetting pancreatic cancer progression. Pancreatology. 2020;20(3):409-418. doi:10.1016/j.pan.2020.01.003

16. Korner M, Christ E, Wild D, et al. Glucagon-like peptide-1 receptor overexpression in cancer and its impact on clinical applications. Front Endocrinol (Lausanne). 2012;3:158. doi:10.3389/ fendo.2012.00158

17. Koehler JA, Kain T, Drucker DJ. Glucagon-like peptide-1 receptor activation inhibits growth and augments apoptosis in murine CT26 colon cancer cells. Endocrinology. 2011;152(9):3362-3372. doi:10.1210/en.2011-1201

18. He L, Law PTY, Wong CK, et al. Exendin-4 Exhibits Enhanced Antitumor Effects in Diabetic Mice. Sci Rep. 2017;7(1):1791. doi:10.1038/s41598-017-01952-5

19. Iwaya C, Nomiyama T, Komatsu S, et al. Exendin-4, a Glucagonlike Peptide-1 Receptor Agonist, Attenuates Breast Cancer Growth by Inhibiting NF-kappaB Activation. Endocrinology. 2017;158 (12):4218-4232. doi:10.1210/en.2017-00461

20. He W, Yu S, Wang L, et al. Exendin-4 inhibits growth and augments apoptosis of ovarian cancer cells. Mol Cell Endocrinol. 2016;436:240-249. doi:10.1016/j.mce.2016.07.032

21. Nie ZJ, Zhang YG, Chang YH, et al. Exendin-4 inhibits glioma cell migration, invasion and epithelial-to-mesenchymal transition through GLP-1R/sirt3 pathway. Biomed Pharmacother. 2018;106:1364-1369. doi:10.1016/j.biopha.2018.07.092

22. Xue X, Lu Z, Tang D, et al. Galectin-1 secreted by activated stellate cells in pancreatic ductal adenocarcinoma stroma promotes proliferation and invasion of pancreatic cancer cells: an in vitro study on the microenvironment of pancreatic ductal adenocarcinoma. Pancreas. 2011;40(6):832-839. doi:10.1097/ MPA.0b013e318217945e

23. Huang J, Shen M, Yan M, et al. Exosome-mediated transfer of miR1290 promotes cell proliferation and invasion in gastric cancer via NKD1. Acta Biochim Biophys Sin (Shanghai). 2019;51(9):900-907. doi:10.1093/abbs/gmz077 
24. Khaleel EF, Badi RM, Satti HH, et al. Exendin-4 exhibits a tumour suppressor effect in SKOVR-3 and OVACR-3 ovarian cancer cells lines by the activation of SIRT1 and inhibition of NF-kappaB. Clin Exp Pharmacol Physiol. 2020;47(6):1092-1102. doi:10.1111/14401681.13288

25. Garg B, Giri B, Modi S, et al. NFkappaB in Pancreatic Stellate Cells Reduces Infiltration of Tumors by Cytotoxic $\mathrm{T}$ Cells and Killing of Cancer Cells, via Up-regulation of CXCL12. Gastroenterology. 2018;155(3):880-891 e888. doi:10.1053/j.gastro.2018.05.051

26. Schnittert J, Bansal R, Mardhian DF, et al. Integrin alpha11 in pancreatic stellate cells regulates tumor stroma interaction in pancreatic cancer. FASEB j. 2019;33(5):6609-6621. doi:10.1096/ fj.201802336R

27. Quail DF, Joyce JA. Microenvironmental regulation of tumor progression and metastasis. Nat Med. 2013;19:1423-1437. doi:10.1038/ nm.3394

28. Yuan Y, Jiang JY, Wang JM, et al. BAG3-positive pancreatic stellate cells promote migration and invasion of pancreatic ductal adenocarcinoma. J Cell Mol Med. 2019;23(8):5006-5016. doi:10.1111/ jcmm. 14352
29. Erkan M, Hausmann S, Michalski CW, et al. The role of stroma in pancreatic cancer: diagnostic and therapeutic implications. Nat Rev Gastroenterol Hepatol. 2012;9(8):454-467. doi:10.1038/ nrgastro.2012.115

30. Habisch H, Zhou S, Siech M, et al. Interaction of stellate cells with pancreatic carcinoma cells. Cancers. 2010;2(3):1661-1682. doi:10.3390/cancers2031661

31. Bachem MG, Schunemann M, Ramadani M, et al. Pancreatic carcinoma cells induce fibrosis by stimulating proliferation and matrix synthesis of stellate cells. Gastroenterology. 2005;128(4):907-921. doi:10.1053/j.gastro.2004.12.036

32. Cui L, Li C, Gao G, et al. FTY720 inhibits the activation of pancreatic stellate cells by promoting apoptosis and suppressing autophagy via the AMPK/mTOR pathway. Life Sci. 2019;217:243-250. doi:10.1016/j.lfs.2018.12.019

33. Gao Z, Wang X, Wu K, et al. Pancreatic stellate cells increase the invasion of human pancreatic cancer cells through the stromal cellderived factor-1/CXCR4 axis. Pancreatology. 2010;10(2-3):186193. doi:10.1159/000236012

\section{Publish your work in this journal}

OncoTargets and Therapy is an international, peer-reviewed, open access journal focusing on the pathological basis of all cancers, potential targets for therapy and treatment protocols employed to improve the management of cancer patients. The journal also focuses on the impact of management programs and new therapeutic agents and protocols on patient perspectives such as quality of life, adherence and satisfaction. The manuscript management system is completely online and includes a very quick and fair peer-review system, which is all easy to use. Visit http://www.dovepress.com/ testimonials.php to read real quotes from published authors. 